\title{
BACTERIAL CONTAMINATION OF HANDS OF MEDICAL INTERNS AND UNDERGRADUATE STUDENTS
}

\author{
SUNANDHA SENTHIL ${ }^{1}$, ASHWINI HEGDE ${ }^{1}$, VAMAN KULKARNI ${ }^{2}$, RADHAKRISHNA ${ }^{1 *}$
}

${ }^{1}$ Department of Microbiology, Kasturba Medical College, Mangalore, Manipal University, Karnataka, India. ${ }^{2}$ Department of Community Medicine, Kasturba Medical College, Mangalore, Manipal University, Karnataka, India. Email: manipuraradhakrishna@yahoo.com

Received: 22 June 2017, Revised and Accepted: 21 August 2017

\section{ABSTRACT}

Objective: Cross-transmission by the hands of health-care workers is considered the main route of spread of nosocomial infections. Awareness among medical students and interns about the importance of hand hygiene practices and facilities for its adherence can play a major role in reducing disease transmission. The objectives of the present study were: (1) To determine the level and type of microbial contamination present on the hands of medical students and interns from a teaching hospital of Mangalore, Karnataka, and (2) to evaluate the relationship between hand contamination and knowledge, attitude, and practices of hand hygiene.

Methods: Swabs were obtained from the dominant hand and the skin surface beneath the rings of participants during their routine work hours. Laboratory analysis was carried out within one hour of collection of samples. The participants were asked to fill a questionnaire on hand hygiene. Descriptive statistics and analysis was done by Chi-square test.

Results: Of the 70 study participants, 35 (50\%) were medical undergraduate students and 35 (50\%) were medical interns. The contamination rate was higher among the undergraduates (91.4\% [32/35]) compared to interns (77.1\% [27/35]). 38 (54\%) participants hands were contaminated with Staphylococcus aureus, of which 17 (44.7\%) were methicillin-resistant S. aureus. Although overall knowledge status about hand hygiene was good, concepts about certain key elements in hand hygiene were not clearly understood by the participants. Knowledge about alcohol-based hand rubs was not up to the mark. The level of knowledge was found to be similar between UGs and interns and between the genders. Wearing ring while handling patients had an influence on hand contamination.

Conclusions: Although the overall knowledge about hand hygiene was good, very few participants knew that hand hygiene after exposure to immediate surroundings of patient can prevent cross-transmission. Health-care workers may unknowingly carry antibiotic-resistant bacteria on their hands. Being unaware of this fact may have serious repercussions as the students and interns may serve as a medium for the spread of nosocomial infections.

Keywords: Bacterial contamination, Hands, Medical interns, Undergraduates.

(C) 2017 The Authors. Published by Innovare Academic Sciences Pvt Ltd. This is an open access article under the CC BY license (http://creativecommons. org/licenses/by/4. 0/) DOI: http://dx.doi.org/10.22159/ajpcr.2017.v10i12.20908

\section{INTRODUCTION}

Hospital-acquired infections are responsible for significant morbidity, mortality, and increase the duration of hospital stay and cost. Cross infection by the hands of health-care workers (iatrogenic infections) is considered the main route of spread of nosocomial infections. Special attention has to be given and institutional policy must be implemented to prevent the transmission of such infections significantly. Practicing regular hand washing after handling the patients may be the most important intervention in infection control [1]. The literature survey suggests that commonly used hand rubs can eliminate common nosocomial pathogens such as Escherichia coli (most frequent cause of catheter associated urinary tract infection), Pseudomonas aeruginosa (cause of ventilator associated pneumonia), Staphylococcus aureus (most frequent cause of surgical site infection), and Staphylococcus epidermidis (most frequent cause of catheter associated bloodstream infection) [2]. Studies done in medical and nursing students in Sri Lanka and India show less compliance toward standard hand hygiene devised by the World Health Organization (WHO) $[3,4]$. Microbial flora was found to be high in those who use rings hence implying that wearing hand jewels is a risk factor for contamination [5]. The emergence of antibiotic resistant bacteria is considered an increasing problem globally and is associated with increased length of hospital stay, health-care costs, patient morbidity, and mortality [6-9]. Mortality among patients with methicillin resistant $S$. aureus (MRSA) and vancomycin-resistant enterococci bacteremia is significantly higher than mortality among patients with susceptible forms of the same bacteria $[10,11]$. Healthcare workers may unknowingly carry antibiotic resistant bacteria on their hands, especially medical students while palpating, percussing and performing procedures. Moreover, during their clinical training, they are posted in infection sensitive areas such as delivery room, intensive care units, and operation theaters, where greater requirements of sterility and infection control are needed [12-14]. Thus, the present study had aimed to assess and identify the type of microbial contamination present on the hands of medical students and interns for determining their role in the transmission of nosocomial infections.

\section{METHODS}

\section{Study setting and design}

This study was a consecutive non-randomized trial. The study population included medical students and interns associated with two governments and one private teaching hospital in Mangalore. The inclusion criteria were medical interns and undergraduate students who consented to take part in the study and those wwho were not interested were excluded.

\section{Sample size}

Sample size was calculated according to the formula:

$\mathrm{n}=\frac{\mathrm{Z}_{\alpha}^{2} \mathrm{pq}}{\mathrm{E}^{2}}$ 
With $90 \%$ confidence interval and $85 \%$ power the sample size came to 65 . However, the study population included in this study was 70 participants [5].

\section{Data and sample collection}

This study was conducted after getting approval from the Institutional Ethics Committee. The method of data collection was purposive sampling (non-randomized sampling). Informed consent was obtained from all participants and a questionnaire was administered to obtain Information about gender, age, and hand washing techniques by the participants. Among the participants, $40(57.14 \%)$ were from government and $30(42.86 \%)$ were from private hospitals. TThe frequencies of ring wearers and non-ring wearers while handling patients were found to be $17(24.29 \%)$ and $53(75.71 \%)$, respectively. Complete confidentiality of the response of the participants was ensured. The swabs were obtained from the dominant hand of participants during their routine working hours and the samples were numbered correspondingly, and transferred to the microbiology laboratory of Kasturba Medical College, Mangalore, for analysis. Additional swabs were taken from the area beneath the ring wearing of the participants. Further, the participants were asked to fill a questionnaire on hand hygiene (adopted from the WHO questionnaire on hand hygiene practice and knowledge among health-care workers).

\section{Identification of pathogen and antibiogram}

The swabs were inoculated on blood agar and McConkey agar and incubated appropriately. Bacteria were identified by evaluating its colony characteristics, microscopy, and biochemical tests. Further, bacterial isolates were subjected to antibiotic sensitivity test by the Kirby-Bauer disk diffusion method as per the Clinical and Laboratory Standards Institute guidelines [15]. Cefoxitin disc was used to detect MRSA. Descriptive statistics and analysis by Chi-square test were done using SPSS version 17.0.

\section{RESULTS AND DISCUSSION}

Among the participants, $35(50 \%)$ medical undergraduate students and $35(50 \%)$ medical interns working for the two hospitals attached to the same medical college were included. The age ranged from 19 to 25 years with the mean being $21.83 \pm 1.43$ years. Among them, $34(48.6 \%)$ were male and $36(51.4 \%)$ were female. The distribution of study participants according to year of study is presented in Fig. 1 and the department-wise distribution of study participants is presented in Fig. 2.

\section{Bacterial contamination rate of hands}

Among the seventy participants, overall contamination rate was found to be $84.3 \%$. The contamination rate was higher among the undergraduates (91.4\%) compared to interns (77.1\%). The contamination rate was found to be higher in male participants $(88.2 \%)$ than in female participants (80.6\%). There was no statistically

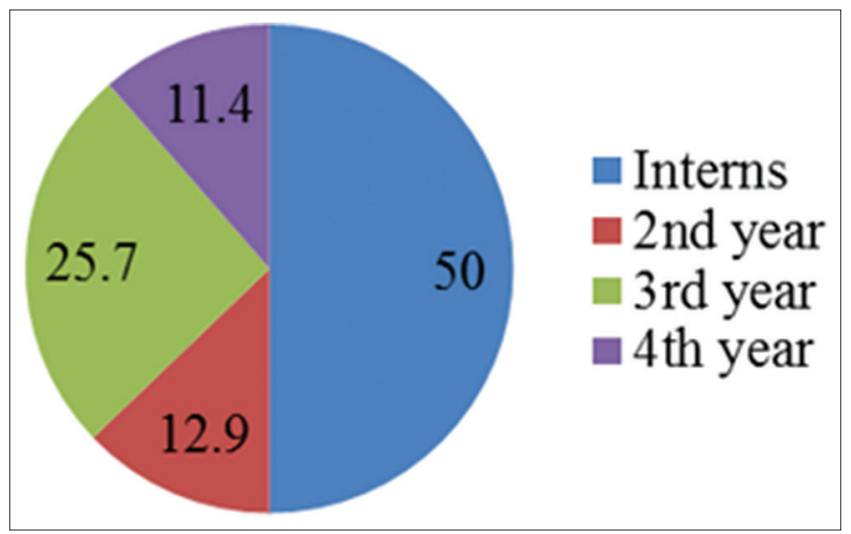

Fig. 1: Distribution of study participants (in percentages) significant difference between the contamination rates of those who had agreed to have received formal training in hand hygiene (83\%) to those who had not received (87\%). The contamination rate was not significantly different between those who used hand rub routinely during posting and those who did not.

\section{Identification of bacteria that contaminate hands}

Among the 70 swabs (from the dominant hand of each participant) that were examined, 38 (54.3\%) were contaminated with S. aureus. Among them, $17(24.3 \%)$ of the 70 swabs were contaminated with MRSA. About 18 of 70 swabs were contaminated with coagulase-negative staphylococci (CoNS). Out of the $43 \mathrm{~S}$. aureus isolates obtained from hand/ring area of hand, 19 (44.18\%) were found to be methicillin resistant.

Of the 70 swabs from hands examined, only one contained Acinetobacter spp. and another hand on one hand and the other hand was found to be contaminated with Klebsiella spp. Among the 17 swabs taken from area of hand in contact with rings, only one was found to contain diphtheroids, whereas the same hand contained CoNS. The comparison of pattern of hand contamination between UG and interns is shown in Table 1. The comparison of pattern of contamination of the area beneath the ring between UG and interns is shown in Table 2.

\section{Antibiotic susceptibility pattern of isolated bacteria}

The antibiotic susceptibility pattern of $S$. aureus and CoNS are depicted in Fig. 3. The only diphtheroids strain isolated from ring area was found to be sensitive to penicillin, cefoxitin, gentamicin, netilmicin, chloramphenicol, erythromycin, tetracycline, clindamycin, cephalothin,

Table 1: Comparison of pattern of hand contamination between UG and interns

\begin{tabular}{llll}
\hline Organism in hand & UG $(\mathbf{n}=\mathbf{3 5}) \mathbf{( \% )}$ & Intern $(\mathbf{n}=\mathbf{3 5})$ & $\mathbf{p}^{*}$ \\
\hline S. aureus & $20(57.14)$ & $18(51.42)$ & 0.192 \\
MRSA & $7(20)$ & $10(28.6)$ & 0.403 \\
CoNS & $10(28.6)$ & $8(22.9)$ & 0.584 \\
\hline
\end{tabular}

*Statistically significant $(\mathrm{p}<0.05)$, S. aureus: Staphylococcus aureus,

MRSA: Methicillin resistant Staphylococcus aureus, CoNS: Coagulase-negative staphylococci

Table 2: Comparison of pattern of contamination of the area beneath ring between UGs and interns

\begin{tabular}{lll}
\hline $\begin{array}{l}\text { Organism isolated beneath } \\
\text { ring area }\end{array}$ & UG $(\mathbf{n}=\mathbf{3 5})$ & Intern $(\mathbf{n}=\mathbf{3 5})$ \\
\hline S. aureus & $3(8.6)$ & $2(5.7)$ \\
MRSA & $2(5.7)$ & 0 \\
CoNS & $6(17.1)$ & $1(2.9)$ \\
\hline
\end{tabular}

S. aureus: Staphylococcus aureus, MRSA: Methicillin-resistant

Staphylococcus aureus, CoNS: Coagulase-negative staphylococci

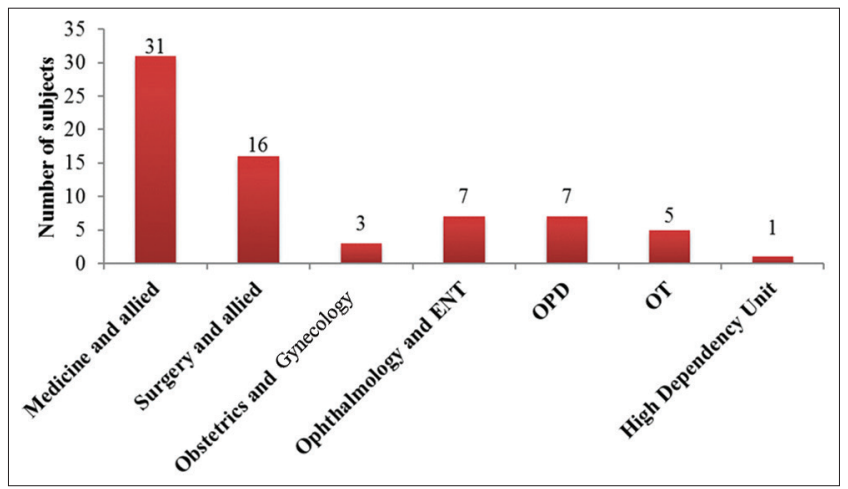

Fig. 2: Department-wise distribution of study participants 
and amoxiclav. Acinetobacter spp. isolated from hand was found to be resistant to ampicillin, cefotaxime, ceftriaxone, and ceftazidime. The Klebsiella spp. isolated was found to be sensitive to ampicillin, amikacin, gentamicin, ceftriaxone, cefotaxime, and CLP (Ceftazidime - $18 \mathrm{~mm}$; CAC - $20 \mathrm{~mm}$ )

Relationship between hand contamination and knowledge, attitude, and practices of hand hygiene

The knowledge, attitude, and practices about the hand contamination was determined and out of 70 participants, $67.1 \%$ had agreed to have received formal training and $84.3 \%$ used alcohol-based hand rub for hand hygiene. The knowledge about the main route of crosstransmission of potentially harmful germs between patients in a healthcare facility is health-care workers' hands were observed among $68.6 \%$ and $34.3 \%$ participants knew that the most frequent source of germs responsible for health-care associated infections is germs already present within a patient. Other responses assessed in the questionnaire based on the WHO are presented below in the Table 3 .

Handling patients by wearing jewelry is considered as a major source of spreading diseases, thereby 56 students knew wearing jewelry favors colonization of hands with harmful germs but 13 out of those 56 wore jewelry while handling patients. Among the undergraduates and interns, $77.14 \%$ and $60 \%$ knew that main route of transmission of nosocomial infections is unclean hands of health-care workers, respectively (Chi-square value $=2.3688$ ). The comparison of knowledge about hand hygiene between interns and UG students is presented below in Table 4 .

\section{DISCUSSION}

This study included 70 participants; among them, contamination rate was found to be $84.3 \%$. The previous study conducted among physicians and dermatologists working in a hospital showed significant contamination of the hands at entry $(59.1 \%)$ and at exit $(90.9 \%)$. The same study depicted the hand contamination rates of medical UGs and interns in which no significant difference was observed [16]. The contamination rate was found to be higher in males compared to females though not statistically significant. This may be due to better adherence to hand hygiene guidelines by the latter [17-19]. Contamination rate was not significantly different between those who used hand rub routinely during posting and those who did not. An earlier study has reported that compared to uncleansed hands, hands cleansed with alcohol-based hand rub were significantly less likely to be contaminated with methicillin-resistant CoNS [20]. The contamination rates of those who agreed to have received formal training in hand hygiene were comparable to those who did not. This could be attributed to the lack of compliance.

In the case of determining the pattern of contamination, $54.3 \%$ of hands were contaminated with $S$. aureus and $44.7 \%$ were found to be MRSA. In another study among health-care professionals, Staphylococcus spp. was the predominant organism isolated [16].In this study, Acinetobacter spp, Klebsiella spp., and diphtheroids were isolated from three different participants and similar scenario was also reported in other study [21]. The antibiotic sensitivity pattern showed almost all the $S$. aureus isolates were sensitive to gentamicin, netilmicin, chloramphenicol, erythromycin, tetracycline, and cephalothin. Out of the total 45 S. aureus isolates obtained from hand/ring area of hand $42.22 \%$ were found to be methicillin-resistant. Health-care professionals have been recognized as potential asymptomatic MRSA carriers [22]. In this study, $72 \%$ of CoNS were found to be resistant to methicillin. Among those, 18 methicillin-resistant CoNS, resistance was observed as 2 for gentamicin, 2 for chloramphenicol, 14 for erythromycin, 8 for tetracycline, 9 for clindamycin, and 3 for cephalothin (D-test negative for 14) and the earlier study showed both lower levels and a narrower spectrum of cross-resistance [23]. Most of the studies supported that all gentamicin resistant strains were sensitive to netilmicin and the same was impregnated in this study, and also no isolates were resistant to netilmicin [23]

Althoughthe overall knowledge status about hand hygiene wasgood, very few participants knew that hand hygiene after exposure to immediate surroundings of patient can prevent cross transmission. Being unaware of this fact may have serious repercussions as the students and interns may carelessly serve as a medium for spread of nosocomial infections,

Table 3: Knowledge about hand hygiene assessed by the WHO-based questionnaire

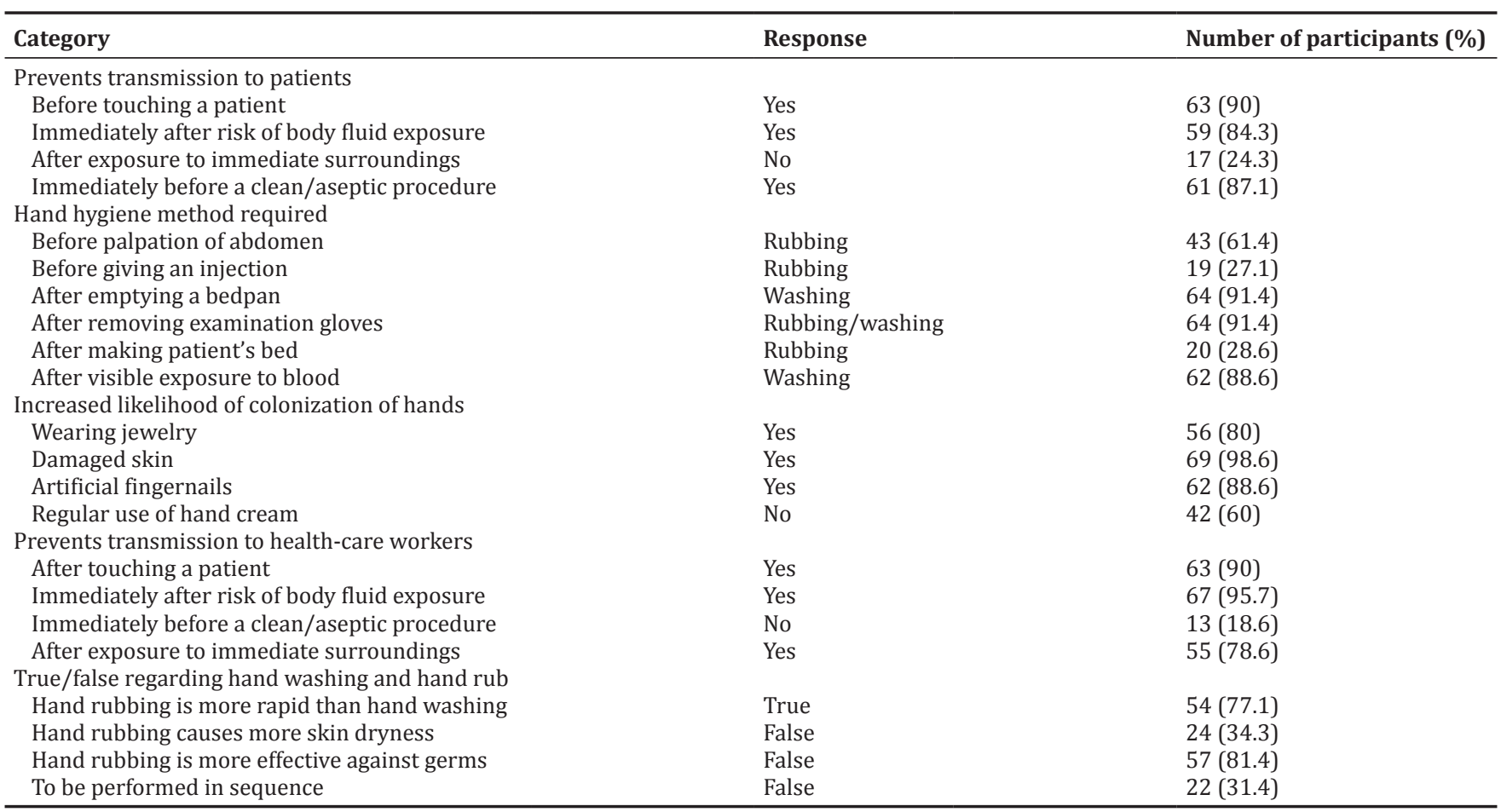

*Statistically significant $(\mathrm{p}<0.05)$, WHO: World Health Organization 
Table 4: Comparison of knowledge between interns and UG students

\begin{tabular}{|c|c|c|c|}
\hline Category & $\begin{array}{l}\text { Frequency of correct response } \\
\text { by UG } \\
n=35(\%)\end{array}$ & $\begin{array}{l}\text { Frequency of correct response } \\
\text { by interns } \\
n=35(\%)\end{array}$ & $\mathbf{p}$ \\
\hline Source of germs & $11(31.4)$ & $13(37.1)$ & 0.615 \\
\hline \multicolumn{4}{|l|}{ Prevents transmission to patients } \\
\hline Before touching a patient & 31 (88.6) & $32(91.4)$ & 0.690 \\
\hline Immediately after risk of body fluid exposure & $31(88.6)$ & $28(80)$ & 0.324 \\
\hline After exposure to immediate surroundings & $9(25.7)$ & $8(22.9)$ & 0.780 \\
\hline Immediately before a clean/aseptic procedure & $28(80)$ & $33(94.3)$ & 0.074 \\
\hline \multicolumn{4}{|l|}{ Hand hygiene method required } \\
\hline Before palpation of abdomen & $22(62.9)$ & $21(60)$ & 0.213 \\
\hline Before giving an injection & $8(22.9)$ & $11(31.4)$ & 0.367 \\
\hline After emptying a bedpan & $31(88.6)$ & $33(94.3)$ & 0.393 \\
\hline After removing examination gloves & $31(88.57)$ & $33(94.3)$ & 0.434 \\
\hline After making patient's bed & $13(37.1)$ & $7(20)$ & 0.077 \\
\hline After visible exposure to blood & $30(85.7)$ & $32(91.4)$ & 0.356 \\
\hline \multicolumn{4}{|l|}{ Increased likelihood of colonization of hands } \\
\hline Wearing jewelry & $25(71.4)$ & $31(88.6)$ & 0.073 \\
\hline Damaged skin & $34(97.1)$ & $35(100)$ & 0.314 \\
\hline Artificial fingernails & $29(82.9)$ & $33(94.3)$ & 0.133 \\
\hline Regular use of hand cream & $22(62.9)$ & $20(57.1)$ & 0.626 \\
\hline \multicolumn{4}{|l|}{ Prevents transmission to health-care workers } \\
\hline After touching a patient & $29(82.9)$ & $34(97.1)$ & $0.046^{*}$ \\
\hline Immediately after risk of body fluid exposure & 33 (94.3) & $34(97.1)$ & 0.555 \\
\hline Immediately before a clean/aseptic procedure & $6(17.1)$ & $7(20)$ & 0.759 \\
\hline After exposure to immediate surroundings & $26(74.3)$ & $29(82.9)$ & 0.382 \\
\hline \multicolumn{4}{|l|}{ True/false regarding hand washing and hand rub } \\
\hline Hand rubbing is more rapid than hand washing & 25 (71.4) & $29(82.9)$ & 0.255 \\
\hline Hand rubbing causes more skin dryness & $9(25.7)$ & $15(42.9)$ & 0.131 \\
\hline Hand rubbing is more effective against germs & $27(77.1)$ & $30(85.7)$ & 0.356 \\
\hline To be performed in sequence & $15(42.9)$ & $7(20)$ & $0.039 *$ \\
\hline
\end{tabular}

particularly to immunocompromised patients [12,24]. In this study, awareness about the importance of rubbing with alcohol-based rub before giving an injection and after making the patient's bed was found to be poor, whereas some studies observed a knowledge deficit in relation to the use of alcohol-based hand rubs to decontaminate hands in the health-care setting [12]. This is important because the future health-care professional should not be misguided by false sense of safety and needs to take precautions to protect themselves to serve the patients better. The current investigation has a perception that hand rubbing causes more skin dryness. This could be one of the reasons for poor compliance and also it was found that many have a misconception that hand rubbing and hand washing are required to be performed in sequence. However, in an earlier study, during routine patient care hand rubbing with an alcohol-based solution was found to be significantly more efficient in reducing hand contamination than hand washing with antiseptic soap [25]. In the current study, knowledge level was found to be similar between UGs and interns. However, there was significantly higher number of UGs who knew that hand hygiene after touching the patient prevents transmission of germs to healthcare workers. UGs who knew that hand washing and hand rubbing were not to be performed in sequence, significantly outnumbered the interns who knew the fact. From the above observations, it can be proposed that education about hand hygiene needs to be reinforced at regular intervals. Frequencies of correct responses for almost all points considered in the questionnaire were comparable between male and female participants However exceptionally higher number of male participants correctly agreed that hand rubbing does not cause more skin dryness than hand washing $[17,19]$. In this study, female participants showed a better self-assessment regarding the knowledge and adherence to hygiene guidelines in comparison to their male counterparts. The contamination rate of hands was $94.1 \%$ in those who wore ring as against $81.1 \%$ among those who did not. In a study conducted among dentists, bacteria and fungi were significantly more frequent in dentist's hand with rings than those without rings (63\% and $37 \%$ respectively) and among the isolated, potentially pathogenic microorganisms were S. aureus, E. coli, and Candida albicans [26]. Another study among nurses, the presence of rings on hands resulted in an increased frequency of hand carriage of S. aureus as well as Gram-negative bacilli [20].

However, contamination rate of hand area beneath ring was significantly higher among UGs when compared to interns. In this study, a significantly higher number of male participants who wore ring had CoNS than their female counterparts. The improved understanding of hand hygiene among students and facilities for its adherence is expected to play a major role in curbing disease transmission. Since antibiotic resistance leads to life-threatening infections, prolonged hospital stays and contributes to economic burden, controlling transmission of resistant strains in hospitals by better hand hygienic extremely important. The need of the hour is to create awareness among medical students and interns about the importance of hand hygiene practices in the prevention of nosocomial infections. It is of prime importance to persuade them to follow the practices and help them in doing so by arranging facilities for the same.

\section{ACKNOWLEDGMENTS}

The authors would like to thank the Manipal University for providing facilities for carrying out this research work.

\section{REFERENCES}

1. Saloojee H, Steenhoff A. The health professional's role in preventing nosocomial infections. Postgrad Med J 2001;77(903):16-9.

2. Kampf G, Löffler H, Gastmeier P. Hand hygiene for the prevention of nosocomial infections. Dtsch Arztebl Int 2009;106(40):649-55.

3. Gunasekara A, Kottahachchi WJ, Fernando W. Knowledge, attitudes and practices of hand hygiene among final year medical and nursing students at the University of Sri Jayewardenepura. Sri Lankan J Infect Dis 2013;3(1):15-25

4. Nair SS, Hanumantappa R, Hiremath SG, Siraj MA, Raghunath P. Knowledge, attitude, and practice of hand hygiene among medical and nursing students at a tertiary health care centre in Raichur, India. ISRN 
Prev Med 2014;2014:608927.

5. Khodavaisy S, Nabili M, Davari B, Vahedi M. Evaluation of bacterial and fungal contamination in the health care workers' hands and rings in the intensive care unit. J Prev Med Hyg 2011;52(4):215-8.

6. Cosgrove SE, Sakoulas G, Perencevich EN, Schwaber MJ, Karchmer AW, Carmeli Y. Comparison of mortality associated with methicillin-resistant and methicillin-susceptible Staphylococcus aureus bacteremia: A meta-analysis. Clin Infect Dis 2003;36(1):53-9.

7. Pelz RK, Lipsett PA, Swoboda SM, Diener-West M, Powe NR, Brower RG, et al. Vancomycin-sensitive and vancomycin-resistant enterococcal infections in the ICU: Attributable costs and outcomes. Intensive Care Med 2002;28(1):692-7.

8. Ken I, Jayshree D, Alison P. Nosocomial infections. Contin Educ Anaesth Crit Care Pain 2005;5(1):14-7.

9. Feather A, Stone SP, Wessier A, Boursicot KA, Pratt C. Now please wash your hands: The handwashing behaviour of final MBBS candidates. J Hosp Infect 2000;45(1):62-4.

10. Wolfensberger A, Durisch N, Mertin J, Ajdler-Schaeffler E, Sax H. Evaluating the tolerability and acceptability of an alcohol-based hand rub - Real-life experience with the WHO protocol. Antimicrob Resist Infect Control 2015;4:18

11. Graf M, Machado A, Mensor L, Zampieri D, Campos R. Surgical hands antisepsis with alcohol based preparations: Cost effectiveness, compliance of professionals and ecological benefits in the Brazilian healthcare scenario. Antimicrob Resist Infect Control 2015;4(1):162-7.

12. van De Mortel TF, Kermode S, Progano T, Sansoni J. A comparison of the hand hygiene knowledge, beliefs and practices of Italian nursing and medical students. J Adv Nurs 2012;68(3):569-79.

13. Cook HA, Cimiotti JP, Della-Latta P, Saiman L, Larson EL. Antimicrobial resistance patterns of colonizing flora on nurses' hands in the neonatal intensive care unit. Am J Infect Control 2007:35(4):231-6.

14. Salisbury DM, Hutfilz P, Treen LM, Bollin GE, Gautam S. The effect of rings on microbial load of health care workers' hands. Am J Infect Control 1997;25(1):24-7.
15. Cheesbrough M. District laboratory practice in Tropical Countries - Part 2. Cambridge, UK: Cambridge University Press; 2005.

16. Paul R, Das NK, Dutta R, Bandyopadhyay R, Banerjee AK. Bacterial contamination of the hands of doctors: A study in the medicine and dermatology wards. Indian J Dermatol Venereol Leprol 2011;77(3):307-13

17. Al Kadi A, Salati SA. Hand hygiene practices among medical students. Interdiscip Perspect Infect Dis 2012;2012:679129.

18. Graf K, Chaberny IF, Vonberg RP. Beliefs about hand hygiene: A survey in medical students in their first clinical year. Am J Infect Control 2011;39(10):885-8.

19. Herbert VG, Schlumm P, Kessler HH, Frings A. Knowledge of and Adherence to hygiene guidelines among medical students in Austria. Interdiscip Perspect Infect Dis 2013;2013:802930.

20. Trick WE, Vernon MO, Hayes RA, Nathan C, Rice TW, Peterson BJ, et al. Impact of ring wearing on hand contamination and comparison of hand hygiene agents in a hospital. Clin Infect Dis 2003;36(1):1383-90.

21. Adams BG, Marrie TJ. Hand carriage of aerobic Gram-negative rods by health care personnel. J Hyg (Lond) 1982;89(1):23-1.

22. Green BN, Johnson CD, Egan JT, Rosenthal M, Griffith EA, Evans MW. Methicillin-resistant Staphylococcus aureus: An overview for manual therapists (). J Chiropr Med 2012;11(1):64-76.

23. Hamilton-Miller JM, Iliffe A. Antimicrobial resistance in coagulasenegative staphylococci. J Med Microbiol 1985;19(2):217-6.

24. Mann CM, Wood A. How much do medical students know about infection control? J Hosp Infect 2006;64(4):366-70.

25. Girou E, Loyeau S, Legrand P, Oppein F, Brun-Buisson C. Efficacy of hand rubbing with alcohol based solution versus standard hand washing with antiseptic soap: Randomised clinical trial. BMJ 2002;325(7360):362.

26. Naeem A, Saluja SA, Krishna D, Shitanshu M, Arun S, Taseer B. Contamination of dentist's hands with and without finger rings. J Int Oral Health 2015;7(8):114-7. 